\title{
Synthesis of High-Reactive Facets Dominated Anatase $\mathrm{TiO}_{2}$
}

\author{
Ci Zhang Wen ${ }^{a}$, Hai Bo Jiang ${ }^{a}$, Shi Zhang Qiao ${ }^{* b}$, Hua Gui Yang ${ }^{* a}$ and Gao Qing (Max) Lu \\ Received (in $X X X, X X X)$ Xth $X X X X X X X X X 200 X$, Accepted Xth $X X X X X X X X X 200 X$ \\ First published on the web Xth $X X X X X X X X X 200 X$ \\ DOI: $10.1039 / b 000000 x$
}

As an important metal oxide, anatase titanium dioxide has been widely investigated because of its many promising properties in catalysis and photocatalysis. The properties of anatase $\mathrm{TiO}_{2}$ crystals are largely determined by external surfaces exposed. Many efforts have been made to improve the percentage of high-reactive facets like $\{001\}$ facets of anatase $\mathrm{TiO}_{2}$ to enhance its catalytic properties. This review reports the recent progress in designing and fabricating high-reactive facets dominated anatase $\mathrm{TiO}_{2}$ via various strategies including traditional vapor phase epitaxial processes, hydrothermal/solvothermal methods, nonhydrolytic alcoholysis methods and high temperature gas phase reactions. Furthermore, focusing on (001) surface, the review also covers advances in the theoretic simulations of various high-reactive facets of anatase $\mathrm{TiO}_{2}$ crystals. Finally, we offer a summary and some perspectives on the challenges and new directions for future research in this emerging frontier.

\section{Introduction}

Metallic and semiconducting nanocrystals with tailored facets have always attracted intense interests in the last decade due to their many intrinsic shape-dependent properties, such as water splitting for hydrogen, solar cells, $\mathrm{CO}_{2}$ reduction, gas sensors etc. ${ }^{1-21}$ As one of the commonly available and most studied metal oxides, titanium dioxide $\left(\mathrm{TiO}_{2}\right)$ has been widely used as a pigment and in sunscreens, paints, ointments, toothpaste, and catalysis. ${ }^{9}$ we have witnessed an exponential growth of research activities since Fujishima and Honda discovered the phenomenon of photocatalytic splitting of water on a $\mathrm{TiO}_{2}$ electrode under ultraviolet (UV) light in1972. ${ }^{22}$ Many promising applications have been developed

\footnotetext{
${ }^{a}$ Key Laboratory for Ultrafine Materials of Ministry of Education, School of Materials Science and Engineering, East China University of Science and Technology, Shanghai 200237, China. Fax: (+86) 21 64252127; E-mail:hyyang@ecust.edu.cn

${ }^{b}$ ARC Centre of Excellence for Functional Nanomaterials, Australian Institute for Bioengineering and Nanotechnology, The University of Queensland, QLD, 4072, Australia.

E-mail:s.qiao@uq.edu.au
}

including photovoltaic cells, photo-/electrochromics, photocatalysis, photonic crystals, and smart surface coatings. ${ }^{5,23,24}$ Synthesis of highly reactive $\mathrm{TiO}_{2}$ is always desired to improve its properties and extending its applications.

$\mathrm{TiO}_{2}$ has three major crystal structures: rutile, anatase and brookite. Of the three phases of $\mathrm{TiO}_{2}$, anatase is the most widely investigated polymorphs because of its high activity in catalysis and photocatalysis. The average surface energies of anatase $\mathrm{TiO}_{2}\left(0.90 \mathrm{~J} / \mathrm{m}^{2}\right.$ for $\{001\}, 0.53 \mathrm{~J} / \mathrm{m}^{2}$ for $\{100\}, 0.44$ $\mathrm{J} / \mathrm{m}^{2}$ for $\left.\{101\}\right)$ have been demonstrated extensively. ${ }^{2,25}$ Unfortunately, $\{101\}$ surfaces, normally the majority of the external surface of anatase $\mathrm{TiO}_{2}$ (more than $94 \%$ percent, according to the Wulff construction), are thermodynamically stable with a low surface energy $\left(0.44 \mathrm{~J} / \mathrm{m}^{2}\right)$, which determines its low reactivity. ${ }^{26}$ To improve its reactivity, the preparation of shape-controlled anatase $\mathrm{TiO}_{2}$ crystals with specific reactive facets exposed is greatly desired, and the minority surfaces such as $\{001\}$ ones with a higher surface energy $\left(0.90 \mathrm{~J} / \mathrm{m}^{2}\right)$ attract extensive interest.

Well-defined anatase single crystals with a high percentage

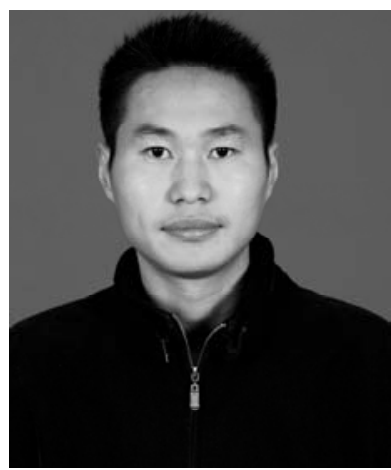

Ci Zhang Wen
Ci Zhang Wen earned his B. E. degree in Materials Science and Engineering from Qingdao University in 2009. Currently he is a master student in East China University of Science and Technology (ECUST) under the supervision of Prof. Hua Gui Yang. His current research focuses on the design, synthesis and characterization of $\mathrm{TiO}_{2}$-based materials for photocatalytic applications.

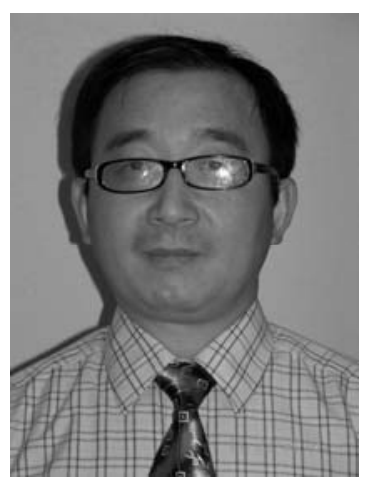

Hai Bo Jiang received his M. S. in 2000 at East China University of Science and Technology (ECUST). He was a research assistant in the National University of Singapore from 2002 to 2004 where his research focused on radar adsorption materials. He completed his Ph.D. in 2008 at ECUST and subsequently joined the faculty as Lecturer. Currently he has interests in the synthesis and characterization of semiconducting crystals.

Hai Bo Jiang 
of $\{001\}$ facets had not been synthesized until we successfully prepared them with $47 \%$ of the highly reactive $\{001\}$ facets by using hydrofluoric acid (HF) as a capping agent under hydrothermal conditions. ${ }^{27}$ Following this breakthrough, extensive efforts have been made in the preparation, modification, and application of $\mathrm{TiO}_{2}$ with $\{001\}$ facets. The percentage of $\{001\}$ facets has been improved steadily and reached as high as $\sim 100 \%$ currently. ${ }^{28-31}$ Meanwhile, the thickness of 2-dimensional (2D) anatase $\mathrm{TiO}_{2}$ nanosheets has reduced to $\sim 1.6 \mathrm{~nm}$ along [001] crystallographic direction, which means that the nanosheets have only two layers of anatase $\mathrm{TiO}_{2}$ crystal units. ${ }^{29}$ By introducing a newly developed gas phase process, anatase $\mathrm{TiO}_{2}$ crystals with a large percentage of $\{001\}$ facets were also fabricated. ${ }^{32}$ Concerning the modification of anatase $\mathrm{TiO}_{2}$ crystals with $\{001\}$ facets, in situ nitrogen doped anatase $\mathrm{TiO}_{2}$ crystals were achieved by employing TiN as the titanium source. ${ }^{33}$ Aside from $\{001\}$ facets, other high-reactive facets such as $\{110\}$ facets were observed recently. ${ }^{34}$ Considering so many

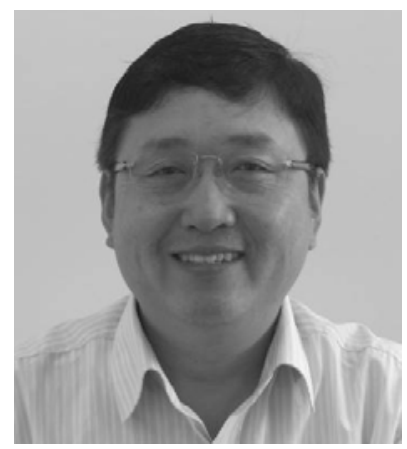

Shi Zhang Qiao received his Ph.D. in Chemical Engineering from the Hong Kong University of Science and Technology. He has worked as Postdoctoral Fellow, Research Fellow, Senior Research Fellow and Associate Professor at The University of Queensland $(U Q)$. He has received several prestigious awards including the UQ Foundation Research Excellence Award, UQ Mid-Career Research Fellowship, ARC APD Fellowship and ARC ARF Fellowship. He has co-authored more than 100 papers

in refereed journals, including Nature, Angew. Chem. Int. Ed., J. Am. Chem. Soc., and Adv. Mater. His research interests include nanomaterials and nanoporous materials for bioseparation, drug/DNA/RNA delivery and energy applications.

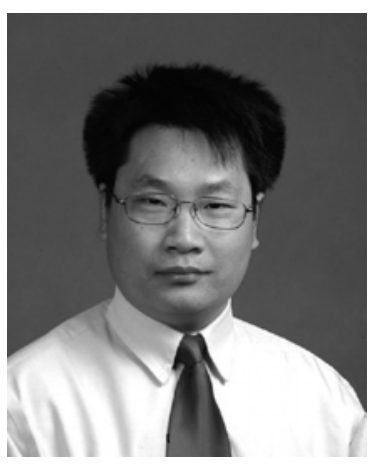

Hua Gui Yang completed his Ph.D. in 2005 at the National University of Singapore. He then joined the General Electric (GE) Company as a Research Scientist and moved to the University of Queensland (UQ) in 2007 as a Postdoctoral Research Fellow. Currently he is a professor of East China University of Science and Technology. His work has been published in top journals such as Nature, and featured in the Nature Materials, RSC Chemistry World and ACS Chemical \& Engineering News. Currently he has interests in

design and synthesis of metallic and semiconducting crystals for renewable clean energy and environmental protection applications.

breakthroughs reported and the fast advances of this field in the past few years, we believe that a comprehensive review of this important functional material will further promote the research in this field. In this feature article, we will focus on the recent synthesis advances, chiefly discussing the various construction methods and the diverse range of raw materials used to prepare anatase $\mathrm{TiO}_{2}$ with reactive facets, and will provide some invigorating perspectives as to future directions.

\section{Theoretic predictions on the morphology of anatase $\mathrm{TiO}_{2}$}

Inorganic single crystals with highly reactive surfaces have long been studied, owing to their importance in scientific research and technological applications. ${ }^{35-37}$ The effect of surface chemistry has been thought to be crucial for the equilibrium morphology of inorganic single crystals and thereby is critical to the synthesis of single crystals with high reactivity. ${ }^{2,26,35-46}$ Anatase $\mathrm{TiO}_{2}$, compared to the other two crystal polymorphs, has been proved to be more reactive in some cases, especially for photocatalysis and catalysis. ${ }^{2,24,47}$ It was found that the most abundant $\{101\}$ facets are not very reactive, and experimental evidence shows that this surface has few defects after annealing in ultrahigh-vacuum conditions (UHV) and thus $\{101\}$ facets of anatase $\mathrm{TiO}_{2}$ are more difficult to reduce in comparison with the widely investigated $\{110\}$ facets of rutile $\mathrm{TiO}_{2}{ }^{47,51}$ Also, many studies have proven that the minor $\{001\}$ facets with high density of surface undercoordinated $\mathrm{Ti}$ atoms exhibit higher reactivity in contrast with $\{101\}$ facets. ${ }^{26,35,44,52}$ So anatase $\mathrm{TiO}_{2}$ crystals with a large percentage of $\{001\}$ facets are very desirable. Thus, as an important environmental and energy material, uniform and highly pure anatase $\mathrm{TiO}_{2}$ single crystals with controllable crystallographic $\{001\}$ facets is vital because of its good performance. For this purpose, efforts have been taken using various adsorbate atoms to change the relative stabilities of different crystal facets and thus alter the

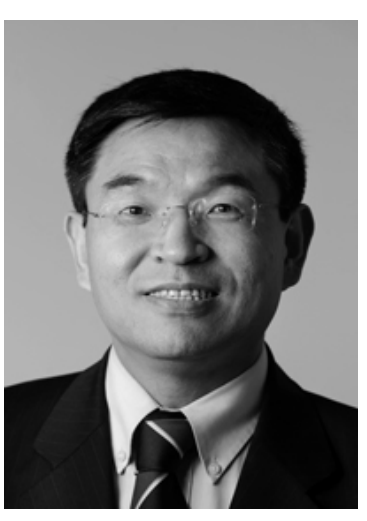

Gao Qing (Max) Lu
Max Lu is currently the Deputy ViceChancellor (Research) at the University of Queensland and Research Director for the ARC Centre of Excellence for Functional Nanomaterials. His research expertise is in nanoparticles and nanoporous materials for clean energy and environmental technologies. Prof Lu is ISI Highly Cited Author in Materials Science, with over 400 papers in high impact journals including Nature, JACS, Angew. Chem., Adv. Mater. (h-index of 47 and over 8800 citations). He has received numerous prestigious awards nationa-

lly and internationally including the Orica Award, RK Murphy Medal, Le Fevre Prize, ExxonMobil Award, IUMRS Young Scientist Award, Top 100 Most Influential Engineers in Australia (2004, 2010). 
equilibrium shapes of anatase $\mathrm{TiO}_{2} \cdot{ }^{9,46,48-50}$

In an early report, Oliver et al. presented some interesting polymorphs of rutile and anatase $\mathrm{TiO}_{2}$ with the evaluation of surface energies. ${ }^{53}\{001\}$ facets of anatase $\mathrm{TiO}_{2}$ with five-coordinate $\mathrm{Ti}$ atoms were found to be adjustable by changing the surface adsorbates. Considering the effect of hydration on equilibrium morphologies, Arrouvel et al. deduced the equilibrium morphologies of anatase $\mathrm{TiO}_{2}$ as a function of the working conditions including temperature and partial pressure of water. ${ }^{52}$ Their idea is that the capability of water adsorptions on (101) or (001) planes varies with the changes of pressure and temperature, thereby resulting in variations of area proportions of the two surfaces.

Barnard et al. established a shape dependent thermodynamic model for a nanoparticle $x$ ( $x$ represents anatase or rutile) on the basis of Gibbs free energy $G_{x}^{o}$ in which the contributions of particle bulk and surface were taken into account. ${ }^{46}$

$$
G_{x}^{o}=G_{x}^{\text {bulk }}+G_{x}^{\text {surface }}
$$

Then they further introduced the surface energy $\gamma_{i}$ for each crystallographic surface $i$. Hence,

$$
G_{x}^{o}=\Delta_{f} G_{x}^{o}+\frac{M}{\rho_{x}}(1-e)\left[q \sum_{i} f_{i} \gamma_{x i}\right]
$$

(a)

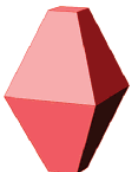

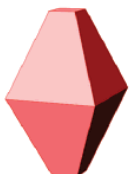

(b)

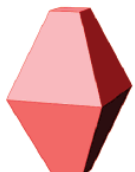

(c)

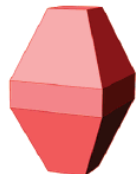

(d)

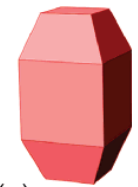

(e)
Fig. 2 Morphology predicted for anatase $\mathrm{TiO}_{2}$ with (a) hydrogenated surfaces, (b) with hydrogen-rich surface adsorbates, (c) hydrated surfaces, (d) hydrogen-poor adsorbates, and (e) oxygenated surfaces. ${ }^{46}$

(a)

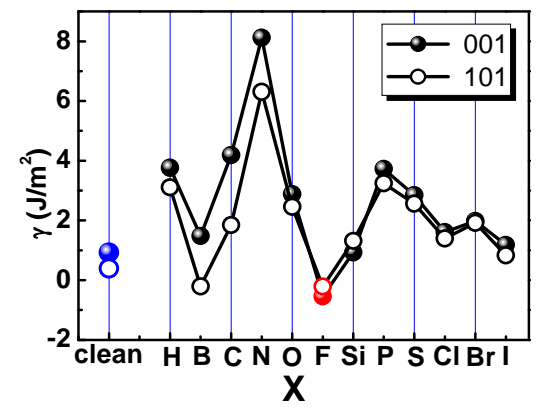

(b)

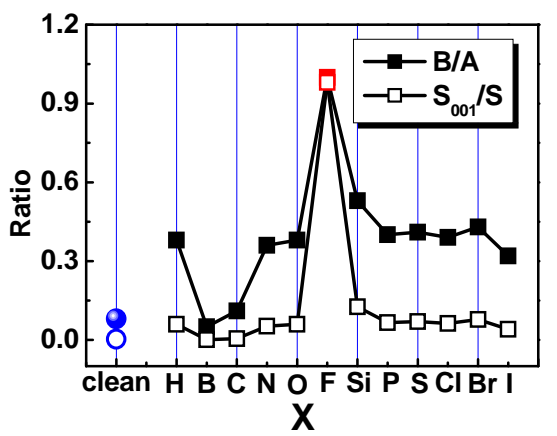

Fig. 3 (a) Calculated energies of the (001) and (101) surfaces surrounded by $X$ atoms. (b) Plots of the optimized value of $\mathbf{B} / \mathbf{A}$ and percentage of $\{001\}$ facets for anatase single crystals with various adsorbate atoms $\mathrm{X}^{27}$
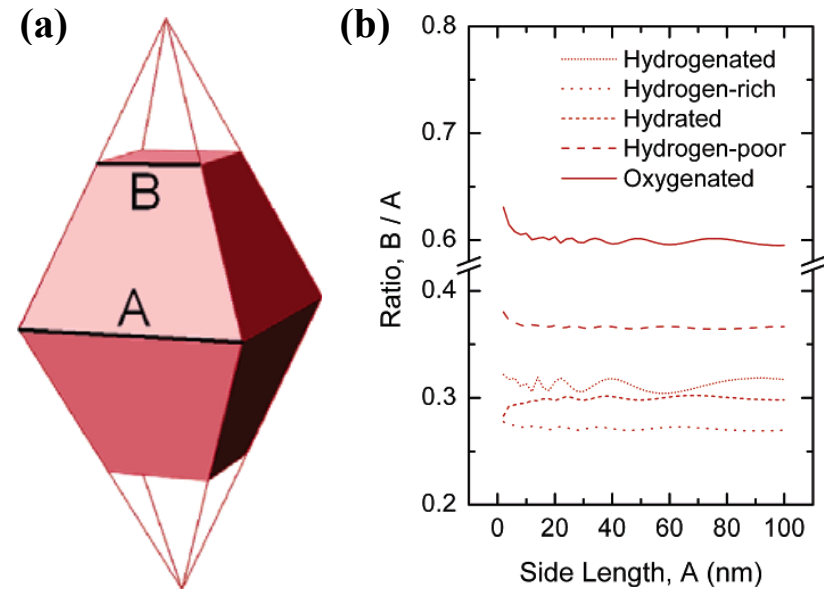

Fig. 1 (a) An anatase tetragonal $\{101\}$ bipyramid is shown in outline, and the side lengths labelled $\mathbf{A}$ and $\mathbf{B}$ are used to define the degree of truncation. (b) Plot of the optimized ratio $\mathbf{B} / \mathbf{A}$ for anatase nanocrystals with each of the various surface chemistries, with a side length $\mathbf{A}=2$ to $100 \mathrm{~nm}$. The facet edges $\mathbf{A}$ and $\mathbf{B}$ are defined in (a). ${ }^{46}$ of anatase $\mathrm{TiO}_{2}$ crystals with different surface chemistry (Fig. 2). From Fig. 2, it can be concluded that surface adsorbates containing a large fraction of hydrogen played a major role in stabilizing anatase nanoparticles.

Thus, inorganic anions acting as important adsorbed species, have attracted great research attention to investigate their role in the shape control of anatase $\mathrm{TiO}_{2}{ }^{50}$ In order to obtain the $\{001\}$ facets dominated anatase $\mathrm{TiO}_{2}$, it was both predicted by first-principle calculations and confirmed through experimental results that termination of $\mathrm{F}$ atoms can yield the lowest surface energy and make $\{001\}$ facets more stable, compared to $\{101\}$ facets. $^{27}$

The most stable crystal facets of anatase $\mathrm{TiO}_{2}$ among oxygenated surfaces are $\{100\}$ facets, while under clean and hydrogenated conditions the $\{101\}$ facets are the most stable. ${ }^{2}$, 26, 46 However, the high surface energies $(\gamma)$ generated by $\mathrm{H}-$ or O-terminated anatase surfaces give rise to the barrier to the formation of large single-crystal $\mathrm{TiO}_{2}$. High values of $\gamma$ are the main reason for high bonding energies $\left(D_{0}\right)$ of $\mathrm{H}-\mathrm{H}(436.0$ 


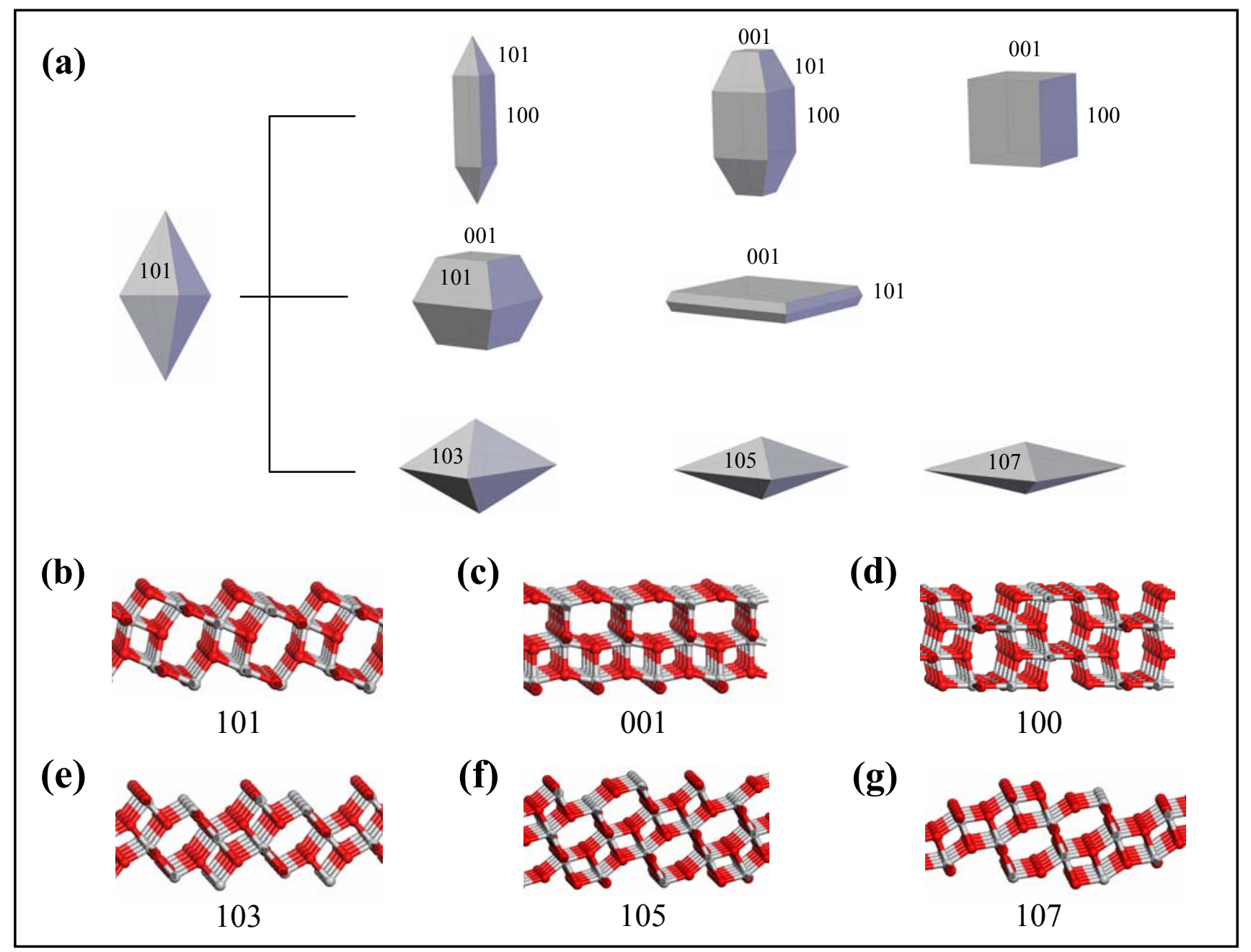

Fig. 4 (a) Morphology evolutions of anatase $\mathrm{TiO}_{2}$ crystals. Representation of atomic schematic structures of (101), (001), (100), (103), (105) and (107) surfaces, respectively. $\mathrm{O}$ in red and $\mathrm{Ti}$ in grey.

$\mathrm{kJ} / \mathrm{mol})$ and $\mathrm{O}-\mathrm{O}(498.4 \mathrm{~kJ} / \mathrm{mol}){ }^{54}$ Therefore, to find a low $D_{0}$ element with strengthened bonding to $\mathrm{Ti}$ was considered to be an effective solution for stabilizing the faceted surfaces. Fortunately, F is such an element, as $D_{0}{ }^{F-F}=158.8 \mathrm{~kJ} / \mathrm{mol}$ and $D_{0}{ }^{F-T i}=569.0 \mathrm{~kJ} / \mathrm{mol}^{54,}{ }^{55}$ To further explore the effects of various adsorbate atoms, a systematic investigation of 12 non-metallic atoms $\mathrm{X}(\mathrm{X}=\mathrm{H}, \mathrm{B}, \mathrm{C}, \mathrm{N}, \mathrm{O}, \mathrm{F}, \mathrm{Si}, \mathrm{P}, \mathrm{S}, \mathrm{Cl}, \mathrm{Br}, \mathrm{I})$ was carried out using first-principle calculations. The calculated $\gamma$ values for different adsorbates are illustrated in Fig. 3a, from which two conclusions can be drawn: (i) among the 12 non-metal-terminated surfaces and the clean surfaces, F-terminated anatase surfaces have the lowest $\gamma$ for both (001) and (101); and (ii) for F-terminated anatase surfaces, (001) surfaces are preferential and more stable, compared to (101) surfaces. These results indicate that a high percentage of anatase $\{001\}$ facets may be achievable if their surfaces are terminated by $\mathrm{F}$ atoms. Furthermore, based on the shape dependent thermodynamic model proposed by Barnard et al., ${ }^{56}$ the optimized ratio $\mathrm{B} / \mathrm{A}$ and the percentage of $\{001\}$ facets can be predicted if $\gamma$ is known. As shown in Fig. 3b, the F-terminated surfaces have the highest degree of truncation and, in turn, the F-terminated surfaces of anatase $\mathrm{TiO}_{2}$ should be dominated by $\{001\}$ facets.

We have verified these theoretical predictions experimentally, which also include a control experiment in the absence of hydrofluoric acid (see Fig. 5). As to the stabilization mechanism, this can be explained by the balance of O-O/O-F repulsions and Ti-O/Ti-F attractions, which could stabilize $\mathrm{Ti}$ and $\mathrm{O}$ atoms on the surfaces. As a summary, some possible morphologies as well as corresponding surface atomic structures of anatase $\mathrm{TiO}_{2}$ crystals are illustrated in Fig. 4, where some of morphologies have been confirmed experimentally, while the others are expected to be realized in the future.

\section{Synthetic strategies of $\{001\}$ facets dominated anatase $\mathrm{TiO}_{2}$}

The different facets of inorganic nanocrystals are largely determined by different surface energies and the surfaces with high reactivity usually diminish rapidly during the growth process as a result of the minimization of total surface energy. Surfaces adsorption of capping agents resulting in different surface energy has been expected to be an effective approach in fabricating faceted nanocrystals, the shape of which are 
hence controlled. The choice of capping agent remains empirical due to the lack of experimental and theoretical evidence on the adsorption energy between capping agents (organic surfactants or non-metallic ions) and nanocrystal surfaces. But undoubtedly, the fact that some organic surfactants and non-metallic ions adsorb selectively on specific facets widely exists. ${ }^{27,53}$ Selective adsorption of capping agents reduces the surface energy of materials with more active sites, and thus retards or inhibits the crystal growth along the corresponding direction, which results in the preservation of high-reactive or high-index facets. As to synthesizing anatase $\mathrm{TiO}_{2}$ with highly reactive $\{001\}$ facets, the high density of undercoordinated $\mathrm{Ti}$ atoms on the surface and large Ti-O-Ti bond angles make some organic surfactants or non-metallic ions adsorb on $\{001\}$ facets preferentially, leading to truncated bipyramid morphology.

Various methods have been developed to synthesize anatase $\mathrm{TiO}_{2}$ crystals dominated with $\{001\}$ facets. Herein, the representative synthetic processes by traditional vapor phase epitaxial processes with $\mathrm{SrTiO}_{3}$ and $\mathrm{LaAlO}_{3}$ as substrates, hydrothermal methods, nonhydrolytic approaches, and high temperature gas phase reactions to prepare anatase $\mathrm{TiO}_{2}$ crystals are reviewed.

\subsection{Traditional vapor phase epitaxial processes by using $\mathrm{SrTiO}_{3}$ and $\mathrm{LaAlO}_{3}$}

Epitaxial growth is defined as oriented overgrowth of a crystalline phase on the surface of a substrate that is also crystalline. The vapor processes such as chemical vapor deposition (CVD), molecular beam epitaxy (MBE), and laser ablation are usually involved in epitaxial growth of (001) anatase films. Chen et al. reported the fabrication of epitaxial anatase films grown on $\mathrm{SrTiO}_{3}$ (001) substrate by metal-organic chemical vapor deposition (MOCVD), which is significant due to the different crystallographic structures and different lattice systems. ${ }^{57}$ The reason for selecting $\mathrm{SrTiO}_{3}(001)$ as a substrate was attributed to the good lattice matching between $\mathrm{SrTiO}_{3}(001)$ $(0.3905 \mathrm{~nm} \times 0.3905 \mathrm{~nm})$ and anatase $(001)(0.3785 \mathrm{~nm} \times 0.3785$ $\mathrm{nm}) .{ }^{58}$ And it was because of the lack of a good structural match between (001) $\mathrm{SrTiO}_{3}$ and all of the major low-index planes of rutile $\mathrm{TiO}_{2}$ that the heteroepitaxial growth of anatase was achieved. Furthermore, the result demonstrated the important role played by the substrate structure on the heteroepitaxial deposition of films and their orientation. Using the same method, Herman et al. prepared the anatase thin film and investigated their electronic and structural properties by X-ray photoelectron spectroscopy (XPS), low energy electron diffraction (LEED), and X-ray photoelectron diffraction (XPD). ${ }^{59}$ The results showed that these thin films had good short-range order on the surface and exhibited high stability. Another investigation using oxygen plasma assisted MBE to grow (001) anatase films on $\mathrm{SrTiO}_{3}(001)$ substrate revealed that $\mathrm{Sr}$ was segregated to the surface during growth with substrate temperature above $823 \mathrm{~K}$. The surface had a $(1 \times 4)$ reconstruction during the growth and this reconstruction remained after cooling to room temperature, confirmed by the high-energy electron diffraction patterns. ${ }^{60}$ Recently, with the assistance of ultrahigh vacuum scanning electron microscopy, Marshall and Castell studied the temperature-dependent shape transitions of epitaxial islands of (001) anatase $\mathrm{TiO}_{2}$ on $\mathrm{SrTiO}_{3}$ (001) substrate. ${ }^{61}$

In order to obtain anatase films with higher quality, (001) face of $\mathrm{LaAlO}_{3}$ substrate was also employed because of its smaller lattice mismatch $(-0.2 \%)$ compared to that of $\mathrm{SrTiO}_{3}(-3.1 \%)$. The as-obtained films exhibited higher crystallinity as expected. Kennedy et al. prepared (001) oriented anatase thin films on both (001) $\mathrm{LaAlO}_{3}$ and (001) $\mathrm{SrTiO}_{3}$ substrates by pulsed laser deposition. ${ }^{62}$ The thickness dependence of the lattice parameter and the crystalline quality of the product were investigated. Considering a wider band gap energy of $\mathrm{LaAlO}_{3}$ substrate $(\sim 5 \mathrm{eV})$, Murakami et al. elucidated the possibility of evaluating the optical properties of anatase films and indicated that high-quality anatase thin film was expected to be a potential material for optical devices. ${ }^{63}$ Phase-pure (001) oriented anatase films on (001) $\mathrm{LaAlO}_{3}$ substrate were also prepared using water vapor as the oxidizing species by reactive agent sputter deposition. ${ }^{64}$ Cheung et al. studied the visible-light driven photocatalytic properties of $\mathrm{N}$-doped $\mathrm{TiO}_{2}(001)$ anatase prepared by plasma-assisted MBE on $\mathrm{LaAlO}_{3}$ (001) substrate, and a substantial red shift in the optical band gap was observed. ${ }^{65}$

\subsection{Hydrothermal/Solvothermal processes}

Hydrothermal method, one of the traditional methods for crystal growth of semiconductors, is frequently used to prepare $\mathrm{TiO}_{2}$ exposed with $\{001\}$ facets. After anatase $\mathrm{TiO}_{2}$ crystals with $47 \%$ of $\{001\}$ facets were successfully synthesized (Fig. 5), ${ }^{27}$ the concept of synergistic functionality was proposed in which 2-propanol was employed as a synergistic capping agent and reaction medium together with $\mathrm{HF}$ to synthesize high-quality anatase $\mathrm{TiO}_{2}$ single-crystal nanosheets with $64 \%$ of the $\{001\}$ facets. ${ }^{66}$ As protecting agent, 2-propanol heterolytically dissociated to form alkoxy groups $\left(\left(\mathrm{CH}_{3}\right)_{2} \mathrm{CHO}^{-}\right)$under acidic conditions and then the groups bound to coordinatively unsaturated $\mathrm{Ti}^{4+}$ cations on $\{001\}$ and $\{101\}$ facets. Selective adsorption of 2-propanol

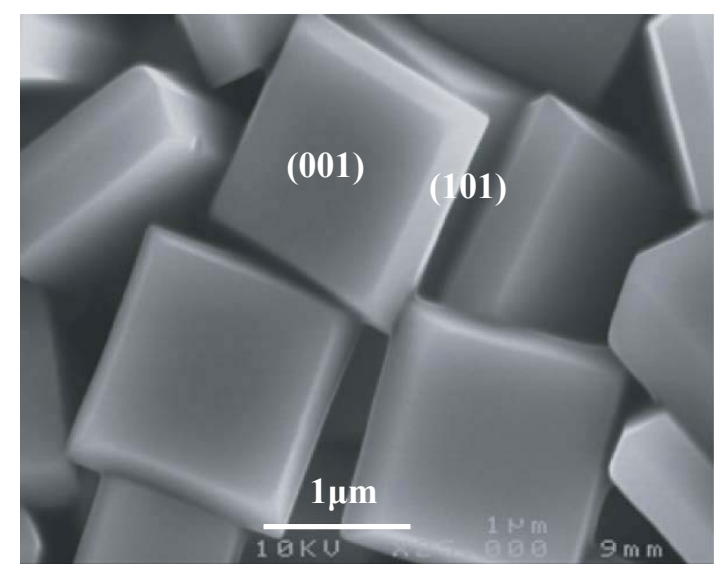

Fig. 5 Typical SEM image of anatase $\mathrm{TiO}_{2}$ nanosheets exposed with $47 \%$ $\{001\}$ facets. $^{27}$ 


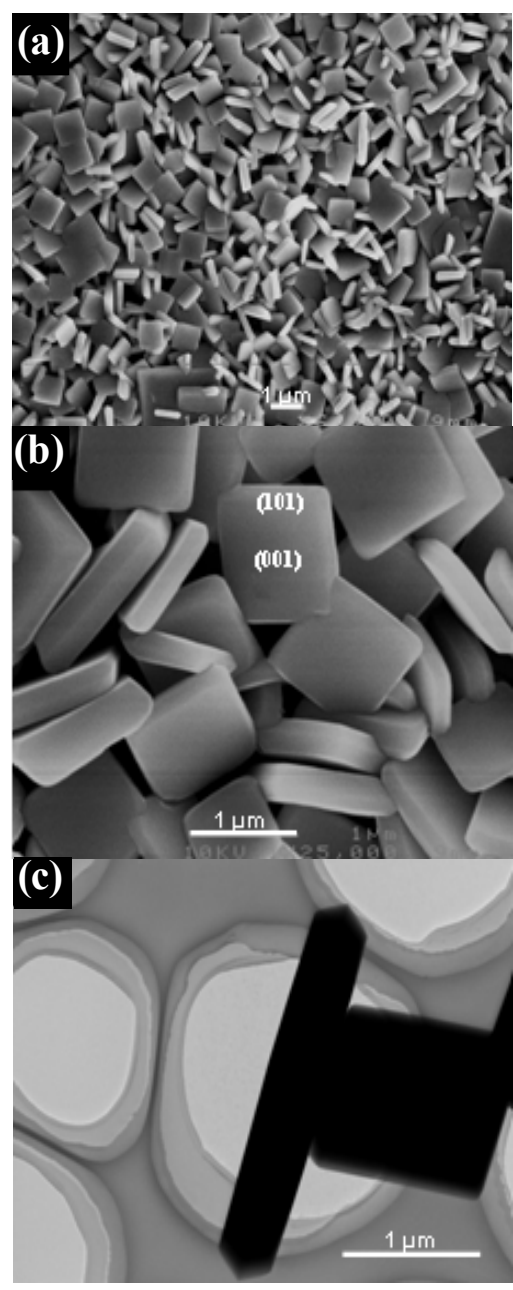

Fig. 6 Typical SEM/TEM images (a-c) of the anatase $\mathrm{TiO}_{2}$ nanosheets synthesized with 2-propanol as a synergistic capping agent. ${ }^{66}$

was favored on $\{001\}$ facets with higher density of 5-fold Ti. As a result, the growth of anatase $\mathrm{TiO}_{2}$ single crystals along [001] direction was retarded. The as-synthesized product exhibited superior photoreactivity 5 times greater than P25, a benchmarking material. Fig. 6 shows the typical TEM/SEM images of the as-synthesized $\mathrm{TiO}_{2}$ single crystalline nanosheets.

In previous studies, large particle size of the synthesized products resulted in a relatively small specific surface area, limiting the improvement in photocatalytic activities. Han et al. improved the percentage of $\{001\}$ facets greatly by using tetrabutyl titanate, $\mathrm{Ti}(\mathrm{OBu})_{4}$, as a precursor and $47 \%$ hydrofluoric acid solution as a capping agent. ${ }^{28,67,68}$ Both high percentage $(89 \%)$ of $\{001\}$ facets and relatively small crystal size (side length $\sim 40 \mathrm{~nm}$, thickness $\sim 6 \mathrm{~nm}$ ) of anatase $\mathrm{TiO}_{2}$ were beneficial for the photocatalytic activity. Then the thinnest anatase $\mathrm{TiO}_{2}$ nanosheets with dominant $\{001\}$ facets $(\sim 1.6 \mathrm{~nm})$ was prepared by Yang et al. recently through a modified hydrothermal route (Fig. 7), ${ }^{29}$ and the efficiency for $\mathrm{H}_{2}$ evolution was achieved as high as $7381 \mu \mathrm{mol} \mathrm{h}{ }^{-1} \mathrm{~g}^{-1}$,
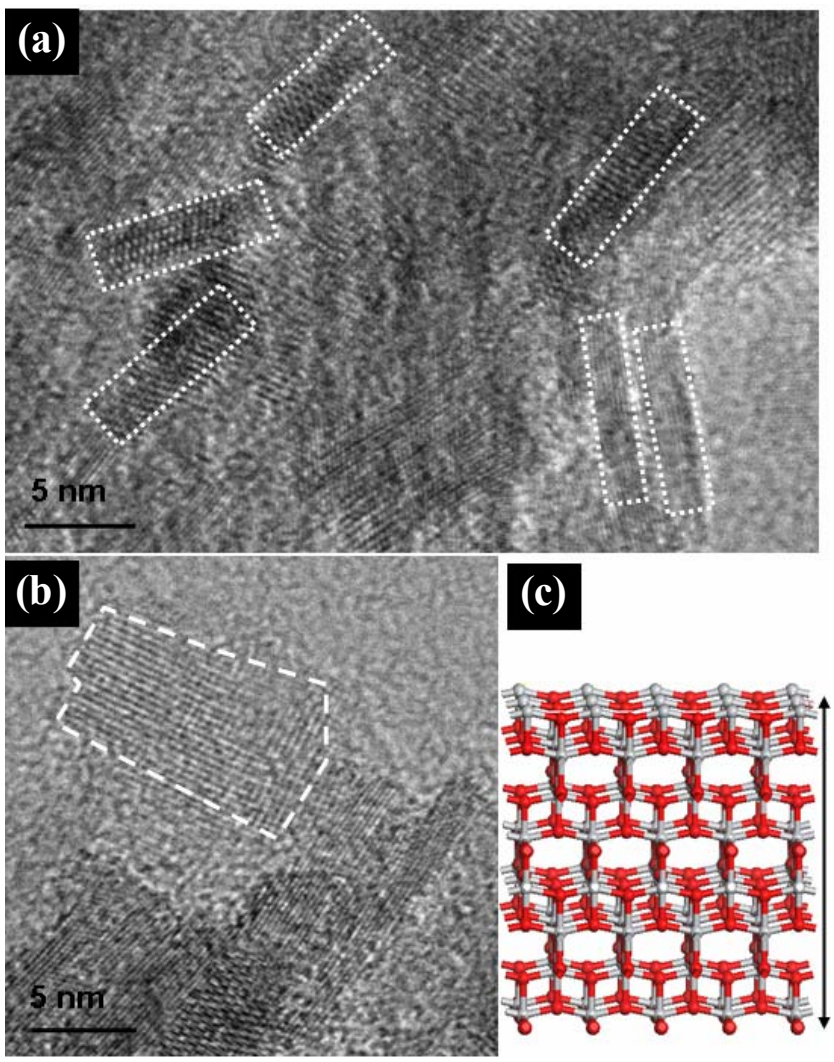

Fig. 7 (a), (b) High-resolution TEM images of ultra-thin anatase $\mathrm{TiO}_{2}$ nanosheets and (c) the corresponding structure model. ${ }^{29}$

under UV-vis light irradiation. This 2D anatase $\mathrm{TiO}_{2}$ nanosheets is novel because it only contains 2 layers of crystal units along [001] crystallographic direction. Another study which realized a shape controlled synthesis of anatase $\mathrm{TiO}_{2}$ with high-reactive facets employ both oleic acid (OA) and oleylamine $(\mathrm{OM})$ as capping agents in the presence of water vapor. ${ }^{69}$ By increasing the amount of oleic acid, anatase $\mathrm{TiO}_{2}$ with $\{001\}$ facets could be preserved (Fig. 8a). It was demonstrated that $\mathrm{OM}$ selectively adsorbed on $\{101\}$ facets while OA on $\{001\}$ facets, resulting in anatase $\mathrm{TiO}_{2}$ crystals exposed with $\{001\}$ facets in the presence of a relatively large amount of OA. Dai et al. introduced electrospinning technique into the synthesis process for the first time to generate $\{001\}$ facets exposed anatase $\mathrm{TiO}_{2} .{ }^{70}$ Before hydrothermal treatment was carried out, nanofibers containing $\mathrm{Ti}$ sources were prepared by electrospinning process, in which small and uniform amorphous $\mathrm{TiO}_{2}$ particles were prepared with the help of poly(vinyl pyrrolidone) (PVP) matrix. The researchers speculated that titanium tetraisopropoxide hydrolyzed with trace moist air in the electrospinning process. The small diameter of the as-spun nanofibers benefited for the diffusion of moist air into the interior of these fibers. The relative slow hydrolysis rate and the PVP matrix resulted in small amorphous $\mathrm{TiO}_{2}$ particles which was beneficial for the conversion from amorphous $\mathrm{TiO}_{2}$ to anatase $\mathrm{TiO}_{2}$ nanocrystals through hydrothermal treatment. The as-obtained nanocrystals exhibited a truncated tetragonal bipyramidal shape with $9.6 \%$ of $\{001\}$ facets exposed 


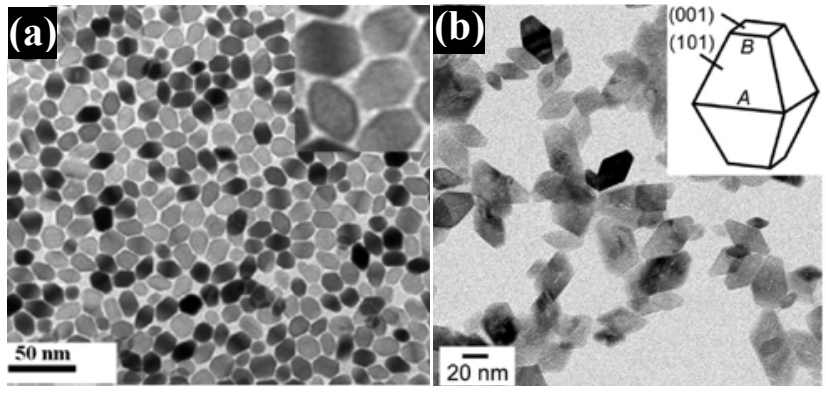

Fig. 8 (a) Truncated rhombic shape anatase $\mathrm{TiO}_{2}$ nanocrystals by Dinh et al. ${ }^{69}$ (b) Truncated tetragonal bipyramid by Dai et al. using electrospinning technique. ${ }^{70}$

(Fig. 8b). Recently, Wang et al. synthesized anatase $\mathrm{TiO}_{2}$ films with oriented $\{001\}$ facets from the pretreated Ti foils. ${ }^{71}$ By using a different titanium source, Liu et al. reported a new method by the hydrothermal synthesis of titanium sulfate $\left(\mathrm{Ti}\left(\mathrm{SO}_{4}\right)_{2}\right)$ and hydrofluoric acid $(\mathrm{HF})$ to produce nanosized $\mathrm{TiO}_{2}{ }^{72}$ Compared to the micron-sized anatase with $72 \%$ of $\{001\}$ facets synthesized in a similar way, these new $\mathrm{TiO}_{2}$ nanoparticles exhibited significantly greater level of photocatalytic activity both for generating $\cdot \mathrm{OH}$ radicals and for watersplitting. In situ nitrogen doped anatase $\mathrm{TiO}_{2}$ crystals with dominant $\{001\}$ facets were also successfully synthesized for the first time (Fig. 9), ${ }^{33}$ which demonstrated excellent photooxidation and photoreduction activity due to the significantly enhanced visible light absorption ability. One-pot synthesis of highly crystalline $\mathrm{TiO}_{2}$ with oxygen deficiency without post-treatment under extreme conditions was realized recently. ${ }^{73}$ The researchers attributed the formation of oxygen-deficient anatase $\mathrm{TiO}_{2}$ sheets to the synergistic functions of $\mathrm{HF}$ and $\mathrm{H}_{2}$ from acid hydrolysis process of $\mathrm{TiB}_{2}$. $\{001\}$ facets were stabilized by surface Ti-F bonds while oxygen vacancies were generated by $\mathrm{H}_{2}$ reduction of $\mathrm{Ti}^{4+}$ on the surface. Oxygen-deficient $\mathrm{TiO}_{2}$ sheets loaded with $\mathrm{Pt}$ nanoparticles shows substantially enhanced photoactivity in hydrogen evolution.

Interestingly, ionic liquid was also proved to be an ideal solvent for the synthesis of $\mathrm{TiO}_{2}$ nanosheets exposed by high-reactive $\{001\}$ facets. 1-butyl-3-methylimidazolium tetrafluoroborate was introduced to create a fluorine-rich $\mathrm{TiO}_{2}$ crystal surfaces through a microwave-assisted process and the as-obtained micrometer-sized $\mathrm{TiO}_{2}$ single crystals with remarkable $80 \%$ of $\{001\}$ facets exhibited much higher catalytic activities for photodegradation of 4-chlorophenol. ${ }^{74}$ Using similar method, biocompatible anatase $\mathrm{TiO}_{2}$ single-crystals with $27-50 \%$ of chemically reactive $\{001\}$ facets were fabricated with another ionic liquid, 1-methyl-imidazolium tetrafluoroborate, and the as-synthesized products were shown to be nontoxic by the experiment using Zebrafish. ${ }^{75}$

Furthermore, some hydrothermal experiments resulted in the anatase $\mathrm{TiO}_{2}$ with special morphologies. Using ammonium bifluoride $\left(\mathrm{NH}_{4} \mathrm{HF}_{2}\right)$ as a morphology controlling agent and $\mathrm{Ti}\left(\mathrm{SO}_{4}\right)_{2}$ as the Ti source, $\mathrm{Yu}$ et al. synthesized tabular-shaped anatase single crystals exposed in micron size and with highly

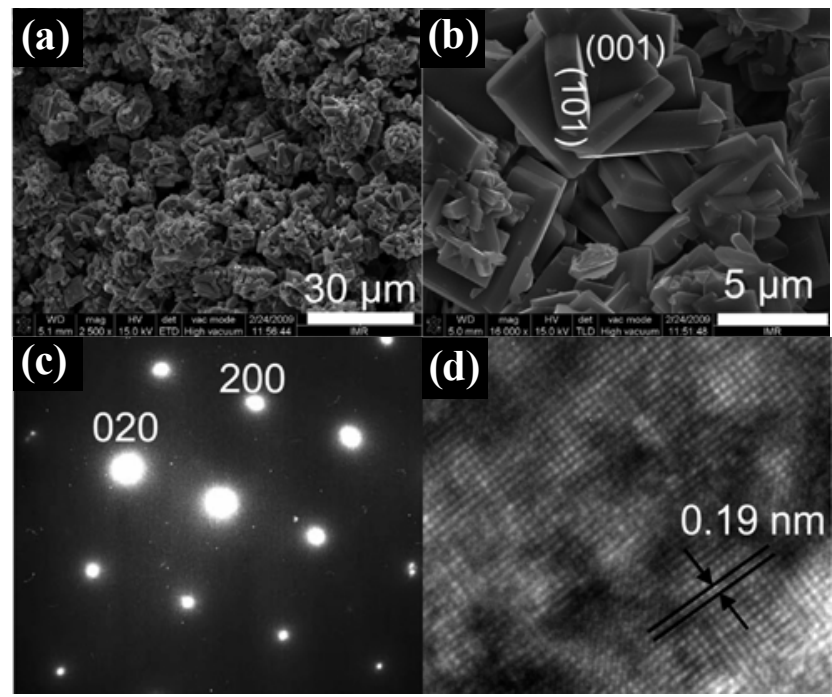

Fig. 9 The SEM/TEM images, and SAED patterns of in situ nitrogen doped anatase $\mathrm{TiO}_{2}$ nanosheets acquired by Liu et al. with $\mathrm{TiN}$ as titanium source. ${ }^{33}$

energetic $\{001\}$ facets. $^{76}$ By adjusting the molar ratio of fluorine to titanium, the morphology, crystallinity, and crystal size could be controlled. The chemical reaction was demonstrated as follows:

$$
\begin{aligned}
\mathrm{NH}_{4} \mathrm{HF}_{2} & \longrightarrow \mathrm{NH}_{4} \mathrm{~F}+\mathrm{HF} \\
4 \mathrm{H}^{+}+\mathrm{TiO}_{2}+6 \mathrm{~F}^{-} & \longrightarrow \mathrm{TiF}_{6}{ }^{2-}+2 \mathrm{H}_{2} \mathrm{O} \\
\mathrm{TiF}_{6}{ }^{2-}+2 \mathrm{H}_{2} \mathrm{O} & \longrightarrow 4 \mathrm{H}^{+}+\mathrm{TiO}_{2}+6 \mathrm{~F}^{-}
\end{aligned}
$$

Similar morphology was also achieved by Liu et al. ${ }^{77}$ They employed ethanol as a stabilizing agent and successfully synthesized hollow $\mathrm{TiO}_{2}$ microspheres containing building units exposed with $\{001\}$ facets. $\mathrm{Hu}$ et al. adopted a hydrothermal method to fabricate single-crystalline anatase $\mathrm{TiO}_{2}$ with unique structures using anodized $\mathrm{TiO}_{2}$ nanotubes as the starting materials and the assembled microspheres were composed of hollow structured particles exposing one $\{001\}$ facet and eight $\{101\}$ facets. ${ }^{78}$ The effect of HF made the wall

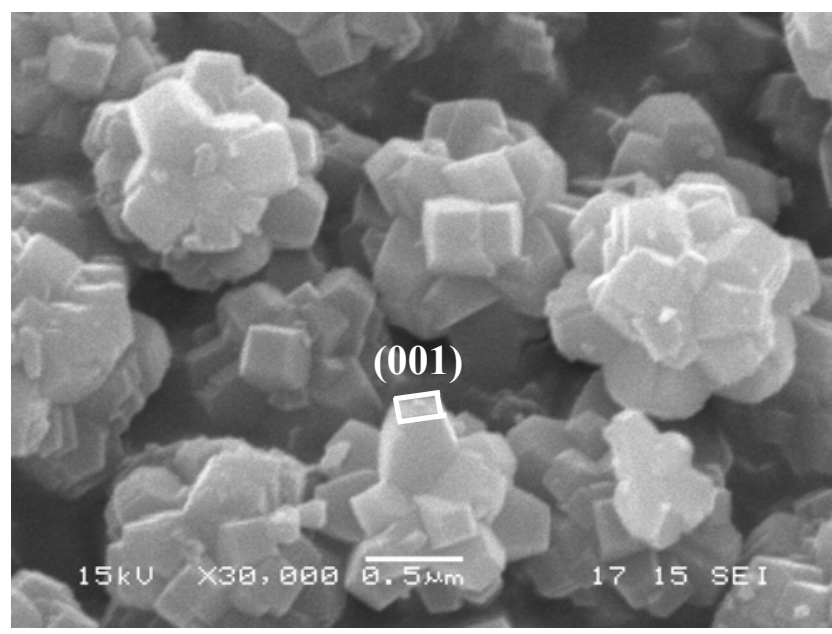

Fig. 10 Multi-twinned anatase $\mathrm{TiO}_{2}$ crystals by Ma et al. ${ }^{80}$ 
of anodized $\mathrm{TiO}_{2}$ nanotubes thinner and meanwhile, higher oxygen pressure was generated inside these nanotubes, which resulted in the fracture of $\mathrm{TiO}_{2}$ nanotubes. Wang et al. employed pretreated tetragonal $\mathrm{ZrO}_{2}$ polycrystalline fibers as a template to synthesize $\mathrm{TiO}_{2}$ particles in $\left(\mathrm{NH}_{4}\right)_{2} \mathrm{TiF}_{6}$ aqueous solution. ${ }^{79}$ After hydrothermal process, remarkable tubular structured materials composed of micro-sized anatase $\mathrm{TiO}_{2}$ crystals were observed. It was speculated that anatase $\mathrm{TiO}_{2}$ particles were deposited and grew on the surfaces of fibers while $\mathrm{ZrO}_{2}$ fibers were gradually corroded, which can be examined from the evolution of XRD patterns of the products synthesized at different reaction time. Besides, Ma et al. synthesized uniform anatase $\mathrm{TiO}_{2}$ crystals with multi-twinned $\{001\}$ facets by using disodium ethylene diamine tetraacetate (EDTA) and F as morphology controlling agents (Fig. 10) ${ }^{80}$ Both F and EDTA played an important role in stabilizing $\{001\}$ facets. It was hypothesized that EDTA $^{4-}$ should exist in the form of stable $[\mathrm{TiO}(\mathrm{EDTA})]^{2-}$ in the reaction medium of $\mathrm{pH}$ value close to 7.0. EDTA $^{4-}$ adsorbed on $\{001\}$ facets preferentially due to higher density of under-coordinated $5 \mathrm{c}-\mathrm{Ti}$ on them in contrast with that on $\{101\}$ facets. So this unique structure was obtained.

\subsection{Nonhydrolytic alcoholysis approaches}

Nonhydrolytic approaches can also produce $\mathrm{TiO}_{2}$ dominated with $\{001\}$ facets. Shan and Demopoulos prepared aqueous well-dispersed and phase-pure anatase $\mathrm{TiO}_{2}$ nanoplatelets with the size of 20-40 nm via controlled hydrolysis of titanium tetrachloride $\left(\mathrm{TiCl}_{4}\right)$ in ethylene glycol. ${ }^{81}$ The reaction mechanism was as follows:

$$
\begin{array}{ccc}
\mathrm{HOCH}_{2} \mathrm{CH}_{2} \mathrm{OH} & \longleftrightarrow \mathrm{CH}_{3} \mathrm{CHO}+\mathrm{H}_{2} \mathrm{O} \\
\mathrm{TiCl}_{4}+2 \mathrm{H}_{2} \mathrm{O} & \longrightarrow & {\left[\mathrm{Ti}(\mathrm{OH})_{\mathrm{x}} \mathrm{Cl}_{\mathrm{n}}\right]^{4-(\mathrm{n}+\mathrm{x})}} \\
\text { or }\left[\mathrm{TiO}_{\mathrm{y}} \mathrm{Cl}_{\mathrm{n}}\right]^{4-(\mathrm{n}+\mathrm{x})} & \longrightarrow & \mathrm{TiO}_{2}+4 \mathrm{HCl}
\end{array}
$$

Water molecules released from reaction (1) can coordinate to $\mathrm{Ti}^{4+}$ cations and then titanium oxy/hydroxychloride complexes $\left(\left[\mathrm{Ti}(\mathrm{OH})_{\mathrm{x}} \mathrm{Cl}_{\mathrm{n}}\right]^{4-(\mathrm{n}+\mathrm{x})}\right.$ or $\left.\left[\mathrm{TiO}_{\mathrm{y}} \mathrm{Cl}_{\mathrm{n}}\right]^{4-(\mathrm{n}+\mathrm{x})}\right)$ were formed. Finally, $\mathrm{TiO}_{2}$ was produced from the polymerization/condensation of these complexes. Another new nonhydrolytic solvothermal alcoholysis approach was developed by Zhu et al. and anatase $\mathrm{TiO}_{2}$ crystals with dominant $\{001\}$ facets were prepared successfully. This process only involved $\mathrm{TiF}_{4}$ as source of $\mathrm{Ti}$ and $\mathrm{F}$ capping agent. ${ }^{82}$ This is a relatively green route compared to the traditional hydrolysis process in HF solution. In addition, $\mathrm{TiO}_{2}$ microspheres composed of anatase $\mathrm{TiO}_{2}$ nanosheets with dominant $\{001\}$ facets (up to 83\%) were synthesized by a simple alcohothermal method, and these $\mathrm{TiO}_{2}$ microspheres exhibited an excellent photocatalytic activity for the degradation of organic contaminants. ${ }^{83}$ Chen et al. synthesized hierarchical structured spheres by the self-organization of anatase $\mathrm{TiO}_{2}$ nanosheets dominated with $\{001\}$ facets through a simple solvothermal method. ${ }^{30}$ Apart from the large percentage of $\{001\}$ facets (nearly $100 \%$ ), small thickness $(\sim 3 \mathrm{~nm})$ and a high specific surface area $(\sim 170$ $\mathrm{m}^{2}$ ) rendered the material unique ability for lithium ion battery applications. Fang et al. also reported a new solvothermal process recently giving rise to three dimensional(3D) hierarchical structures of single-crystalline

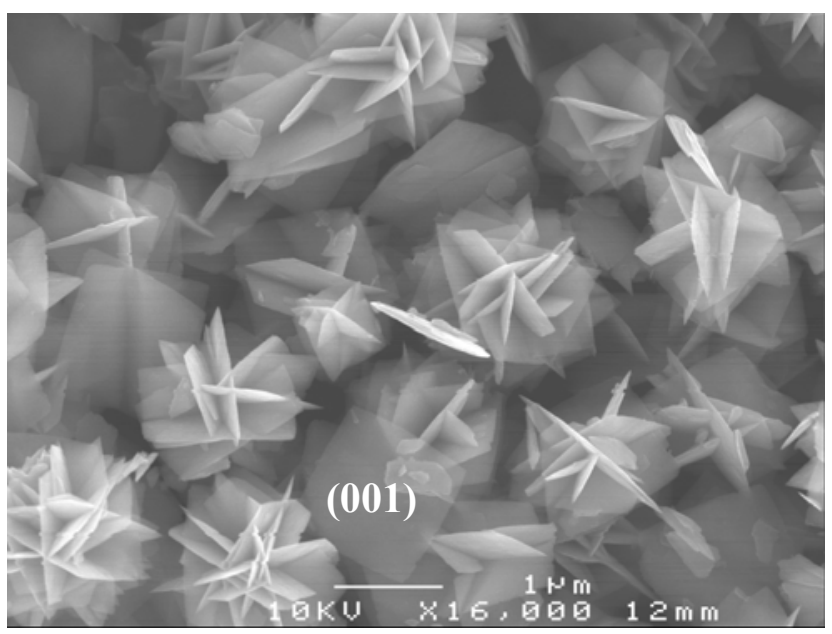

Fig. 11 Three dimensional hierarchical structures of anatase $\mathrm{TiO}_{2}$ nanosheets by Fang et al. ${ }^{31}$

anatase $\mathrm{TiO}_{2}$ nanosheets dominated with well-faceted $\{001\}$ facets (Fig. 11). ${ }^{31}$ Based on these experimental results, Fang et al. concluded that this unique structure was attributed to isobutyl alcohol acting as the reaction media, which might change the growth behavior of anatase $\mathrm{TiO}_{2}$ nanosheets units and their mutual interactions as well.

\subsection{High temperature gas phase oxidation techniques}

A special gas-phase process developed by Amano et al. successfully fabricated faceted decahedral single-crystalline anatase particles with sizes of 50-250 nm for the first time (Fig. 12). ${ }^{32}$ The as-synthesized products exhibited extremely high photocatalytic activity for $\mathrm{H}_{2}$ evolution from an aqueous methanol solution and the oxidative decomposition of organic compounds in an aqueous solution. It was postulated that the scarcity of crystalline defects might have induced these superior properties.

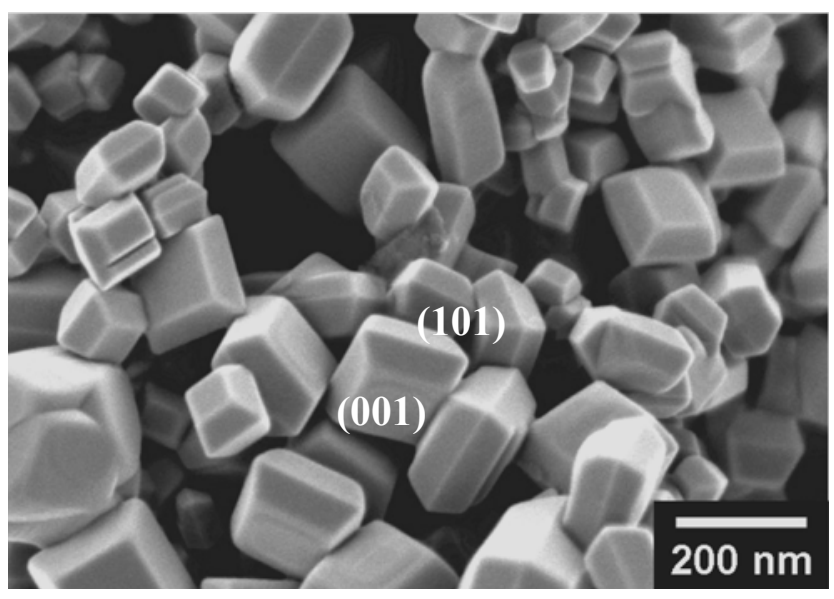

Fig. 12 Anatase $\mathrm{TiO}_{2}$ crystals dominated with $\{001\}$ facets by a gas phase process. ${ }^{32}$

\subsection{Other methods}


Alivov and Fan have realized the transformation of $\mathrm{TiO}_{2}$ nanotubes to truncated pyramid-like-shaped $\mathrm{TiO}_{2}$ nanoparticles with a high percentage of photocatalytically active $\{001\}$ facets after thermal annealing in ambient fluorine. ${ }^{84}$ This method was quite different from the hydrothermal route employed by $\mathrm{Hu}$ et al. ${ }^{78}$ and the size of nanoparticles was controllable, ranging from $20 \mathrm{~nm}$ to $500 \mathrm{~nm}$ by changing fluorine concentration during annealing process. More details of this transformation were further provided by studying the initial stages of the process. ${ }^{85}$ Liu et al. prepared a unique yolk-shell structured particle with $\{001\}$ faceted anatase $\mathrm{TiO}_{2}$ as shells and Mo nanoparticles as cores by the arc-discharge method. ${ }^{86}$ The as-obtained sample displayed enhanced photocatalytic efficiency, which was consistent with the result of UV-visible absorption spectra.

\section{Synthetic strategies of other high-reactive facets dominated anatase $\mathrm{TiO}_{2}$}

Interestingly, besides $\{001\}$ facets, other unusual reactive facets such as $\{110\}$ and $\{100\}$ facets of anatase $\mathrm{TiO}_{2}$ were also observed. The highest-surface-energy $\{110\}$ facets were observed by Liu et al. in the controlled synthesis of anatase $\mathrm{TiO}_{2}$ single crystals from Ti powders (Fig. 13a). ${ }^{34}$ This was the first time that $\{110\}$ facets were observed on anatase $\mathrm{TiO}_{2}$ single crystals where a high percentage of $\{001\}$ facets was also concurrently observed. Wu et al. synthesized nanostructured anatase $\mathrm{TiO}_{2}$ with high-energy $\{001\}$ facets via a nonaqueous synthetic route. ${ }^{87}$ Simultaneously, they tailored the reaction process by introducing a trace amount of water and then the pure $\{010\}$ facets exposed rhombic anatase nanocrystals were acquired on the basis of a hydrolysis mechanism. Most recently, anatase $\mathrm{TiO}_{2}$ crystals with photocatalytic active $\{100\}$ facets were also synthesized using solid Na-titanates as a Ti source under hydrothermal condition (Fig. 13b). ${ }^{88}$ At the beginning, $\mathrm{Ti}(\mathrm{OH})_{4}$ fragments, hydroxyl and sodium ions were produced on the surface of Na-titanates, and then anatase $\mathrm{TiO}_{2}$ nuclei was formed by the arrangement of $\mathrm{Ti}(\mathrm{OH})_{4}$ fragments through dehydration reaction. Then the hydroxyl ions selectively adsorbed on anatase $\{100\}$ facets in the growth process of anatase $\mathrm{TiO}_{2}$ nuclei and thus $\{100\}$ facets were preserved. These reports are

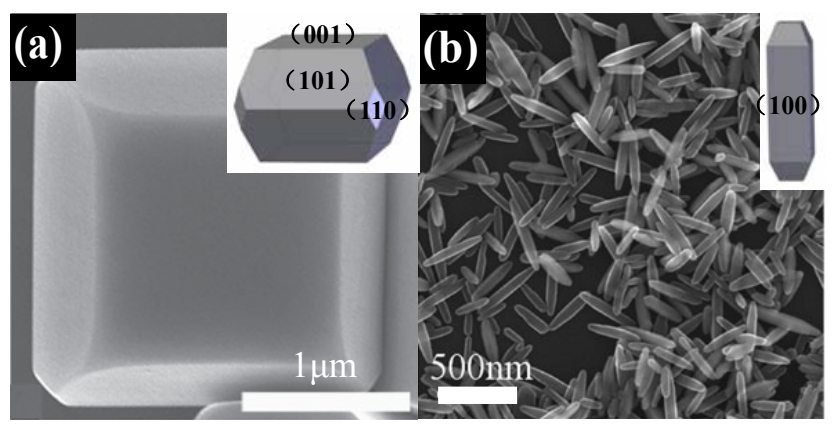

Fig. 13 (a) Anatase $\mathrm{TiO}_{2}$ single crystals with $\{110\}$ facets and a large percentage of $\{001\}$ facets. $^{34}$ (b) Anatase $\mathrm{TiO}_{2}$ single crystals exposed with $\{100\}$ facets. $^{88}$ very significant and may open the pathway to deeper understanding the synthetic strategies for anatase $\mathrm{TiO}_{2}$ exposed with other high-reactive facets.

\section{Summary and outlook}

Understanding and controlling the morphology of single crystals plays a key role for the synthesis of high-quality materials with defined surface properties. This article summarizes the synthetic chemistry of anatase $\mathrm{TiO}_{2}$ with high-energy facets, especially with the first-principle calculations predicting the thermodynamically stable crystal morphology and various novel synthesis strategies developed to fulfill the high-energy facets in the past few years.

In spite of the rapid development in the recent past of the theoretical predictions as well as the experimental results for the anatase $\mathrm{TiO}_{2}$ with high-energy facets, many challenges exist in several aspects. For example, Herman et al. reported the reconstruction of (001) surface under ultrahigh-vacuum conditions (UHV), which strongly stabilizes the high-energy surface and largely reduces its reactivity as well. ${ }^{45}$ In this respect, examining the status of possible reconstruction of these high-energy facets is necessary and avoiding the reconstruction through novel synthesis method is highly desirable. Furthermore, considering $\mathrm{TiO}_{2}$ crystals are being generally used as a model system to explore numerous important surface phenomena on atomic scale, synthesis of high-quality large size anatase $\mathrm{TiO}_{2}$ single crystals is also very useful for surface science study. Importantly, almost all the synthesis methods reported to prepare anatase $\mathrm{TiO}_{2}$ crystals with high-energy facets used F-containing compounds as capping agents to control the morphology, which is quite toxic and corrosive. Thus it is highly desirable to develop a new synthesis strategy with reduced or no fluorine containing compounds as capping agents. More importantly, organic surfactants adsorbing onto the surfaces can also remarkably change the free energy of these surfaces and interfacial properties, but the choice of surfactant remains empirical due to many unsolved issues including a quantitative description of the adsorption behaviour and in-depth understanding of selective surface-adsorption energies on nanocrystals. The more complex capping agents might be also a practical solution to create anatase $\mathrm{TiO}_{2}$ crystals with highly-reactive facets. High-index facets can be also expected to be prepared in the future through theoretical predictions and experimental design. Apart from these challenges, liquid phase epitaxial process might be a useful technique to generate the 2-dimensional structured anatase $\mathrm{TiO}_{2}$ exposed by $\{001\}$ facets using substrates with suitable lattice spacing such as $\mathrm{SrTiO}_{3}$. In conclusion, it could be expected that both opportunities and challenges exist for the synthesis of anatase $\mathrm{TiO}_{2}$ with high-energy facets, and a better understanding and controlling of the synthesis process will be the key to further breakthroughs in this emerging front of research.

\section{Acknowledgements}

This work was financially supported by Scientific Research 
Foundation of East China University of Science and Technology (YD0142125), Pujiang Talents Programme and Major Basic Research Programme of Science and Technology Commission of Shanghai Municipality (09PJ1402800, 10JC1403200), Shuguang Talents Programme of Education Commission of Shanghai Municipality (09SG27), National Natural Science Foundation of China (20973059, 91022023, 21076076), Fundamental Research Funds for the Central Universities (WJ0913001), Program for New Century Excellent Talents in University (NCET-09-0347) and the Australian Research Council (ARC) through Discovery Project program (DP1095861, DP0987969).

\section{References}

1. T. L. Thompson and J. T. Yates, Chem. Rev., 2006, 106, 4428.

2. U. Diebold, Surf. Sci. Rep., 2003, 48, 53.

3. U. Bach, D. Lupo, P. Comte, J. E. Moser, F. Weissortel, J. Salbeck, H. Spreitzer and M. Grätzel, Nature, 1998, 395, 583.

4. W. Macyk and H. Kisch, Chem. Eur. J., 2001, 7, 1862.

5. M. Grätzel, Nature, 2001, 414, 338.

6. M. Anpo, S. Dohshi, M. Kitano, Y. Hu, M. Takeuchi and M. Matsuoka, Annu. Rev. Mater. Res., 2005, 35, 1.

7. K. Maeda, K. Teramura, D. L. Lu, T. Takata, N. Saito, Y. Inoue and K. Domen, Nature, 2006, 440, 295.

8. Z. G. Zou, J. H. Ye, K. Sayama and H. Arakawa, Nature, 2001, 414, 625 .

9. X. Chen and S. S. Mao, Chem. Rev., 2007, 107, 2891.

10. P. V. Kamat, J. Phys. Chem. C, 2007, 111, 2834.

11. A. Kudo and Y. Miseki, Chem. Soc. Rev., 2009, 38, 253.

12. R. Asahi, T. Morikawa, T. Ohwaki, K. Aoki and Y. Taga, Science, 2001, 293, 269.

13. S. M. Liu, L. M. Gan, L. H. Liu, W. D. Zhang and H. C. Zeng, Chem. Mater., 2002, 14, 1391.

14. D. Grosso, C. Boissiere, B. Smarsly, T. Brezesinski, N. Pinna, P. A. Albouy, H. Amenitsch, M. Antonietti and C. Sanchez, Nature Mater., 2004, 3, 787.

15. Y. Sakatani, D. Grosso, L. Nicole, C. Boissiere, G. J. D. A. Soler-Illia and C. Sanchez, J. Mater. Chem., 2006, 16, 77.

16. E. Martinez-Ferrero, Y. Sakatani, C. Boissiere, D. Grosso, A. Fuertes, J. Fraxedas and C. Sanchez, Adv. Funct. Mater., 2007, 17, 3348

17. D. Li and Y. N. Xia, Nano Lett., 2003, 3, 555.

18. M. Law, L. E. Greene, J. C. Johnson, R. Saykally and P. D. Yang, Nature Mater., 2005, 4, 455.

19. C. A. Grimes, J. Mater. Chem., 2007, 17, 1451.

20. G. K. Mor, O. K. Varghese, M. Paulose, K. Shankar and C. A. Grimes, Solar Energy Mater. Solar Cells, 2006, 90, 2011.

21. X. G. Han, M. S. Jin, S. F. Xie, Q. Kuang, Z. Y. Jiang, Y. Q. Jiang, Z. X. Xie and L. S. Zheng, Angew. Chem., 2009, 121, 9344.

22. A. Fujishima and K. Honda, Nature, 1972, 238, 37.

23. A. Hagfeldt and M. Grätzel, Chem. Rev., 1995, 95, 49.

24. A. L. Linsebigler, G. Q. Lu and J. T. Yates, Chem. Rev., 1995, 95, 735 .

25. M. Lazzeri, A. Vittadini and A. Selloni, Phys. Rev. B, 2002, 65, 119901.

26. M. Lazzeri, A. Vittadini and A. Selloni, Phys. Rev. B, 2001, 63, 155409.
27. H. G. Yang, C. H. Sun, S. Z. Qiao, J. Zou, G. Liu, S. C. Smith, H. M. Cheng and G. Q. Lu, Nature, 2008, 453, 638.

28. X. Han, Q. Kuang, M. Jin, Z. Xie and L. Zheng, J. Am. Chem. Soc., 2009, 131, 3152.

29. X. H. Yang, Z. Li, G. Liu, J. Xing, C. Sun, H. G. Yang and C. Li, CrystEngComm, DOI: 10.1039/c0ce00233j.

30. J. S. Chen, Y. L. Tan, C. M. Li, Y. L. Cheah, D. Luan, S. Madhavi, F. Y. C. Boey, L. A. Archer and X. W. Lou, J. Am. Chem. Soc., 2010, 132, 6124.

31. W. Q. Fang, J. Z. Zhou, J. Liu, Z. G. Chen, C. Yang, C. H. Sun, G. R. Qiao, J. Zou, S. Z. Qiao and H. G. Yang, Chem. Eur. J., DOI: $10.1002 /$ chem. 200 .

32. F. Amano, O. O. Prieto-Mahaney, Y. Terada, T. Yasumoto, T. Shibayama and B. Ohtani, Chem. Mater., 2009, 21, 2601.

33. G. Liu, H. G. Yang, X. Wang, L. Cheng, J. Pan, G. Q. Lu and H. M. Cheng, J. Am. Chem. Soc., 2009, 131, 12868.

34. M. Liu, L. Piao, L. Zhao, S. Ju, Z. Yan, T. He, C. Zhou and J. Wang, Chem. Commun., 2010, 46, 1664.

35. A. Vittadini, A. Selloni, F. P. Rotzinger and M. Grätzel, Phys. Rev. Lett., 1998, 81, 2954.

36. A. Vittadini, M. Casarin and A. Selloni, Theor. Chem. Acc., 2007, 117, 663 .

37. M. Lazzeri and A. Selloni, Phys. Rev. Lett., 2001, 87, 266105.

38. N. Tian, Z. Y. Zhou, S. G. Sun, Y. Ding and Z. L. Wang, Science, 2007, 316, 732.

39. O. Bikondoa, C. L. Pang, R. Ithnin, C. A. Muryn, H. Onishi and G. Thornton, Nature Mater., 2006, 5, 189.

40. O. Dulub, M. Batzilln, S. Solovev, E. Loginova, A. Alchagirov, T. E. Madey and U. Diebold, Science, 2007, 317, 1052.

41. X. Q. Gong, A. Selloni, M. Batzill and U. Diebold, Nature Mater., 2006, 5, 665.

42. A. G. Thomas, W. R. Flavell, A. R. Kumarasinghe, A. K. Mallick, D. Tsoutsou, G. C. Smith, R. Stockbauer, S. Patel, M. Grätzel and R. Hengerer, Phys. Rev. B, 2003, 67, 035110.

43. L. Kavan, M. Grätzel, S. E. Gilbert, C. Klemenz and H. J. Scheel, J. Am. Chem. Soc., 1996, 118, 6716.

44. X. Q. Gong and A. Selloni, J. Phys. Chem. B, 2005, 109, 19560.

45. G. S. Herman, M. R. Sievers and Y. Gao, Phys. Rev. Lett., 2000, 84, 3354.

46. A. S. Barnard and L. A. Curtiss, Nano Lett., 2005, 5, 1261.

47. U. Diebold, N. Ruzycki, G. S. Herman and A. Selloni, Catal. Today, 2003, 85, 93.

48. A. Zaban, S. T. Aruna, S. Tirosh, B. A. Gregg and Y. Mastai, $J$. Phys. Chem. B, 2000, 104, 4130.

49. J. W. Jun, M. F. Casula, J. H. Sim, S. Y. Kim, J. Cheon and A. P. Alivisatos, J. Am. Chem. Soc., 2003, 125, 15981.

50. F. Izumi, Bull. Chem. Soc. Jpn, 1978, 51, 1771.

51. U. Diebold, Surf. Sci. Rep., 2002, 293, 1.

52. C. Arrouvel, M. Digne, M. Breysse, H. Toulhoat and P. Raybaud, J. Catal., 2004, 222, 152.

53. P. M. Oliver, G. W. Watson, E. T. Kelsey and S. C. Parker, J. Mater. Chem., 1997, 7, 563.

54. K. F. Zmbov and J. L. Margrave, J. Phys. Chem., 1967, 71, 2893.

55. K. P. Huber and G. Herzberg, Molecular Spectra and Molecular Structure. IV. Constants of Diatomic Molecules (V. N. Reinhold, New York, 1979, 642). 
56. A. S. Barnard and P. Zapol, J. Chem. Phys., 2004, 141, 4276.

57. S. Chen, M. G. Mason, H. J. Gysling, G. R. Paz-Pujalt, T. N. Blanton, T. Castro, K. M. Chen, C. P. Fictorie, W. L. Gladfelter, A. Franciosi, P. I. Cohen and J. F. Evans, J. Vac. Sci. Technol. A, 1993, 11, 2419.

58. F. S. Galasso, Structure and Properties of Inorganic Solids (Pergamon, New York, 1970).

59. G. S. Herman, Y. Gao, T. T. Tran and J. Osterwalder, Surf. Sci., 2000, 447, 201.

60. G. S. Herman and Y. Gao, Thin Solid Films, 2001, 397, 157.

61. M. S. J. Marshall and M. R. Castell, Phys. Rev. Lett., 2009, 102, 146102.

62. R. J. Kennedy and P. A. Stampe, J. Crystal Growth, 2003, 252, 333.

63. M. Murakami, Y. Matsumoto, K. Nakajima, T. Makino, Y. Segawa, T. Chikyow, P. Ahmet, M. Kawasaki and H. Koinuma, Appl. Phys. Lett., 2001, 78, 2664.

64. B.-S. Jeong, D. P. Norton, J. D. Budai and G. E. Jellison, Thin Solid Films, 2004, 446, 18.

65. S. H. Cheung, P. Nachimuthu, M. H. Engelhard, C. M. Wang and S. A. Chambers, Surf. Sci., 2008, 602, 133.

66. H. G. Yang, G. Liu, S. Z. Qiao, C. H. Sun, Y. G. Jin, Z. Zou, S. C. Smith, H. M. Cheng and G. Q. Lu, J. Am. Chem. Soc., 2009, 131, 4078 .

67. J. S. Chen and X. W. Lou, Electrochem. Commun., 2009, 11, 2332.

68. C. H. Sun, X. H. Yang, Y. S. Chen, Z. Li, X. W. Lou, C. Li, S. C. Smith, G. Q. Lu and H. G. Yang, Chem. Commun., 2010, 46, 6129.

69. C. T. Dinh, T. D. Nguyen, F. Kleitz and T. D. Do, ACS Nano, 2009, 3, 3737.

70. Y. Q. Dai, C. M. Cobley, J. Zeng, Y. M. Sun and Y. N. Xia, Nano Lett., 2009, 9, 2455.
71. X. Wang, G. Liu, L. Wang, J. Pan, G. Q. Lu and H. M. Cheng, J. Mater. Chem., DOI: 10.1039/c0jm02694h.

72. G. Liu, C. Sun, H. G. Yang, S. C. Smith, L. Wang, G. Q. Lu and H. M. Cheng, Chem. Commun., 2010, 46, 755.

73. G. Liu, H. G. Yang, X. Wang, L. Cheng, H. Lu, L. Wang, G. Q. Lu and H. M. Cheng, J. Phys. Chem. C., 2009, 113, 21784.

74. D. Zhang, G. Li, X. Yang and J. C. Yu, Chem. Commun., 2009, 29, 4381 .

75. D. Zhang, G. Li, H. Wang, K. M. Chan and J. C. Yu, Cryst. Growth Des., 2010, 10, 1130.

76. J. Yu, Q. Xiang, J. Ran and S. Mann, CrystEngComm, 2010, 12, 872.

77. S. Liu, J. Yu and M. Jaroniec, J. Am. Chem. Soc., 2010, 132, 11914.

78. X. Hu, T. Zhang, Z. Jin, S. Huang, M. Fang, Y. Wu and L. Zhang, Cryst. Growth Des., 2009, 9, 2324.

79. X. Wang, B. Huang, Z. Wang, X. Qin, X. Zhang, Y. Dai and M. H. Whangbo, Chem. Eur. J., 2010, 16, 7106.

80. X. Y. Ma, Z. G. Chen, S. B. Hartono, H. B. Jiang, J. Zou, S. Z. Qiao and H. G. Yang, Chem. Commun., 2010, 46, 6608.

81. G. B. Shan and G. P. Demopoulos, Nanotechnology, 2010, 21, 025604.

82. J. Zhu, S. Wang, Z. Bian, S. Xie, C. Cai, J. Wang, H. Yang and H. Li, CrystEngComm, 2010, 12, 2219.

83. Z. Zheng, B. Huang, X. Qin, X. Zhang, Y. Dai, M. Jiang, P. Wang and M. H. Whangbo, Chem. Eur. J., 2009, 15, 12576.

84. Y. Alivov and Z. H. Fan, J. Phys. Chem. C, 2009, 113, 12954.

85. Y. Alivov and Z. H. Fan, Nanotechnology, 2009, 20, 405610.

86. X. Liu, D. Geng, X. Wang, S. Ma, H. Wang, D. Li, B. Li, W. Liu, Z. Zhang, Chem. Commun., 2010, 46, 6956.

87. B. Wu, C. Guo, N. Zheng, Z. Xie and G. D. Stucky, J. Am. Chem. Soc., 2008, 130, 17563.

88. J. M. Li and D. S. Xu, Chem. Commun., 2010, 46, 2301. 